\title{
Detection and Identification of Tranquilizer in Biological and Non-Biological Samples in Case of Tigress with History of Homicide
}

\author{
CHARANSING B. GHOTI*, SWATI V. SONDE, KESHAV S. KAPGATE, \\ AJIT R. KOKARE, SHIVANGI S. APTE and VIJAY J. THAKRE
}

Regional Forensic Science Laboratory, Home Department, Government of Maharashtra, Dhantoli, Nagpur-440012, India

charan.ghoti12@gmail.com

Received 22 May 2019 / Accepted 3 July 2019

\begin{abstract}
In India, Tigers, Leopards or any wild animals are inhibited in human dominated area to prevent harm to people as well as wild animals. If any wild animals enter in human dominated area, in such cases to save human beings from wild animals like Tigers, generally emergency immobilizations have to be carried with anesthetic drug i.e., ketamine and xylazine. Usually their mixture is used for immobilization of wild animals. A rare case of Tigress with attempt of immobilization using dart of anesthetic drug was received first time in forensic science laboratory, Nagpur for simultaneous detection of ketamine and xylazine in biological and non biological samples. As per routine toxiclogical analysis of biological (Viscera, Muscle, Skin and blood) and non-biological (Dart with Needle) samples was performed by thin layer chromatography and confirmed by gas chromatographymass spectroscopy (GCMS). The TLC and GC-MS examination revealed presence of anesthetic drug Ketamine and Xylazine in muscle piece, skin piece and dart with needle.
\end{abstract}

Keywords: Forensic science, Tranquilizer, Ketamine, Xylazine, GC-MS, Biological samples

\section{Introduction}

Ketamine[ $\left(\mathrm{C}_{13} \mathrm{H}_{16} \mathrm{ClNO}\right)$, 2-(2-chlorophenyl)-2-(methylamino)cyclohexanone] is widely used as an anesthetic drug. It was introduced commercially for clinical use in 1970 as a useful for short procedures. It is a cyclohexamine group compound and it is a rapid-acting general anesthetic drug used as a sedative for minor surgery in humans and tranquilizer in animals ${ }^{1,2}$. Ketamine stimulates cardiovascular function in normal animals, causing an increase in heart rate and arterial blood pressure. The use of ketamine as a sole anesthetic has been limited by muscle hyper tonicity and myoclonus, violent recovery and the occasional occurrence of convulsions ${ }^{3}$. It is a unique intravenous anesthetic drug that produces a wide spectrum of pharmacological effects including sedation, catalepsy, somatic analgesia, bronchodilator and sympathetic nervous system stimulation ${ }^{4}$. 
Xylazine $\left(\mathrm{C}_{12} \mathrm{H}_{16} \mathrm{~N}_{2} \mathrm{~s}\right)$, [N-(2,6-dimethylphenyl)-5,6-dihydro- $4 \mathrm{H}$-1,3-thiazin-2-amine] is a powerful tranquillizer, which is commonly used to sedate large animals. It is absorbed, metabolized and eliminated extremely rapid. The drug has anesthetic and muscle relaxing properties and extent of these effects may vary in intensity depending on the administrating $\operatorname{dose}^{5,6}$.

Ketamine combined with xylazine has been recommended as a short term anesthetic drug for use in cattle. The combination of both drug is safe and provides excellent anesthesia, muscle relaxation and reasonably stable ${ }^{7}$. Hence, use of ketamine combined with xylazine is preferred for immobilization of wild animals.

\section{Experimental}

A portion $50 \mathrm{~g}$ of each visceral tissue (Pieces of Stomach, Kidney, Lungs, Heart, Liver, Brain and Spleen) was taken. Visceral tissue cut into fine pieces and the sample individually minced properly, alkalinized with $1 \mathrm{M}$ sodium hydroxide. Then, $50 \mathrm{~mL}$ of diethyl ether dichloromethane $(7: 3 \mathrm{v} / \mathrm{v})$ was added. The contents were kept for $2 \mathrm{~h}$ and filtered with Whatman filter paper. Each sample filtrate was then extracted separately with diethyl ether dichloromethane. The solvent extract was transferred into an evaporating dish and again aqueous phase re-extracted with diethyl ether dichloromethane. The extracts were combined and the solvent evaporated at room temperature.

Similarly, a portion of $20 \mathrm{~g}$ of received dart site skin and about $50 \mathrm{~g}$ of dart site muscle piece were taken and cut into fine pieces, alkalinized with $1 \mathrm{M}$ sodium hydroxide. Then, same extraction procedure was applied for above samples.

\section{Extraction procedure for blood samples}

About $15 \mathrm{~mL}$ heart blood and thoracic blood samples were taken alkalinized with $1 \mathrm{M}$ sodium hydroxide. Then, $15 \mathrm{~mL}$ of diethyl ether-dichloromethane $(7: 3 \mathrm{v} / \mathrm{v})$ was added and centrifuged for $5 \mathrm{~min}$ at $2000 \mathrm{rpm}$. The organic layer was transferred into an evaporating dish and the solvent evaporated at room temperature.

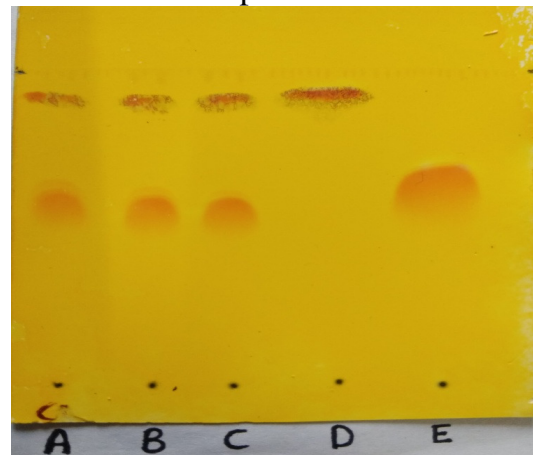

Figure 1. TLC showing spot of ketamine and xylazine
A) Muscle piece extract
B) Skin piece extract
C) Dart with needle extract
D) Ketamine standard
E) Xylazine standard

As per routine forensic toxicological analysis, biological and non biological samples are generally analyzed by thin layer chromatography (TLC). The organic extracts of biological 
and non biological samples were spotted on TLC plates with fine capillary tubes along with ketamine and xylazine standard. The plates were dried and developed in a presaturated tank containing the solvent system chloroform: methanol (90:10, by volume). After developing the plates, the extra solvent was evaporated (dried) in fume hood and the plates were sprayed with Dragendorff's chromogenic spray reagent. It showed orange colour spot for extract of muscle piece, skin piece and dart with needle which tallied with standard Ketamine and Xylazine at $\mathrm{R}_{\mathrm{f}}=0.91$ and 0.56 respectively (Figure 1) and TLC analysis of blood and other viscera samples did not give positive response with Dragendorff's chromogenic spray reagent. Detection of Ketamine and Xylazine in biological and non biological samples received was finally confirmed by GC-MS.

\section{Case history}

The locals near Pandharkawda forest area, Yavatmal district (Maharashtra state, India) have been living under the terror of man-eating tigress officially known as T1, who was believed to have turned a man-eater and killed about 13 people in the last two years in Yavatmal. High court releases the order which permitted the forest department to tranquillize or shoot a man- eating tigress $\mathrm{T} 1$.

Tigress was eliminated as per provisions of wildlife protection act 1972 and brought to wildlife rescue centre to conduct post-mortem (Figure 2, 3 and 4). At the time of postmortem, viscera (Whole Stomach (Figure 5) and Pieces of Kidneys (Figure 6), Lungs (Figure 7), Heart (Figure 8), Liver (Figure 9), Brain (Figure 10), Spleen (Figure 11)), Heart Blood (Figure 12), Thoracic Blood (Figure 13), Darted site muscle Piece (Figure 14), Dart with collared needle along with pierced Skin Piece samples (Figure 15) were preserved and sent for chemical analysis.

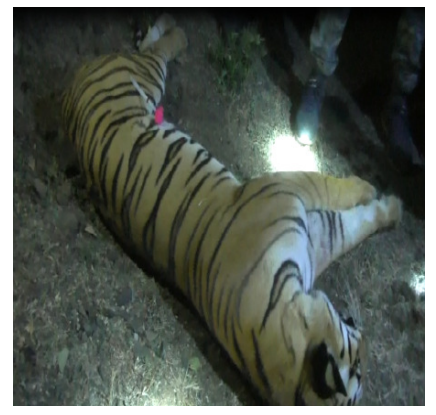

Figure 2

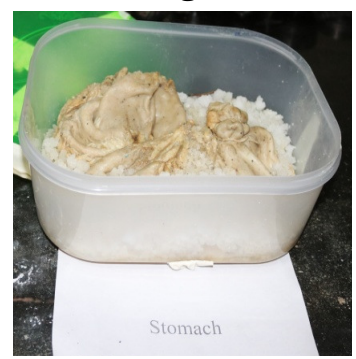

Figure 5. Stomach

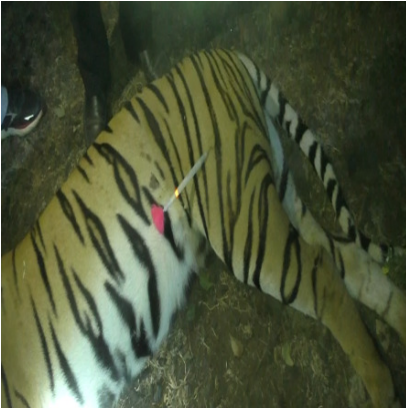

Figure 3

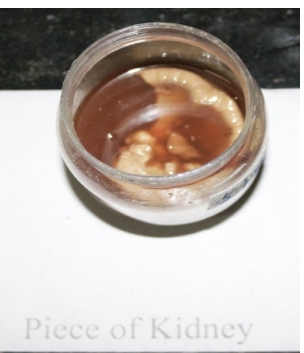

Figure 6. Kidney

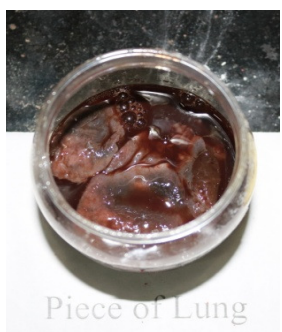

Figure 7. Lungs

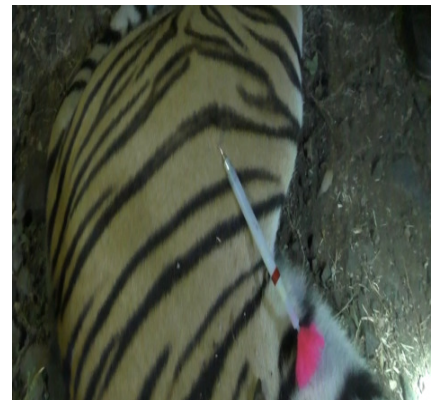

Figure 4

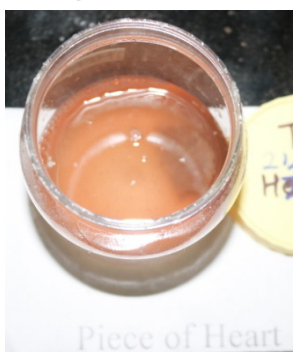

Figure 8. Heart 


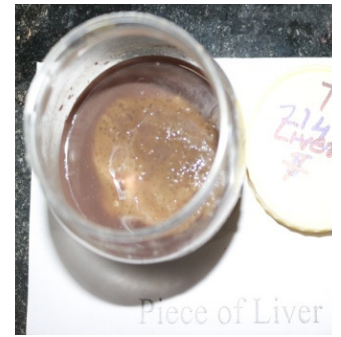

Figure 9. Liver

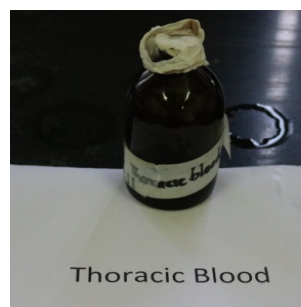

Figure 13. Thoracic blood

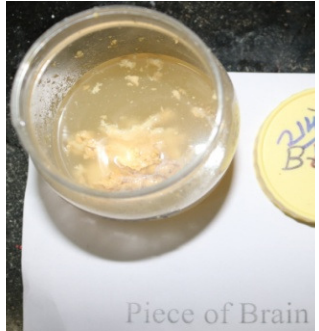

Figure 10. Brain
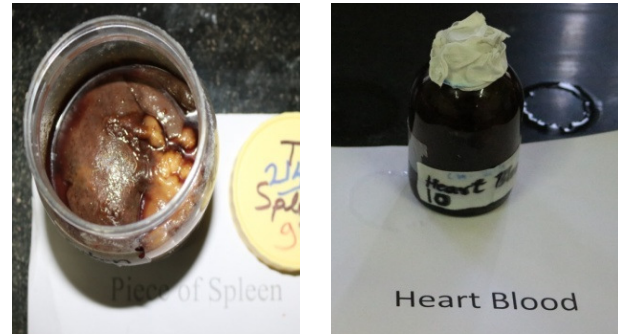

Figure 11. Spleen Figure 12. Heart blood

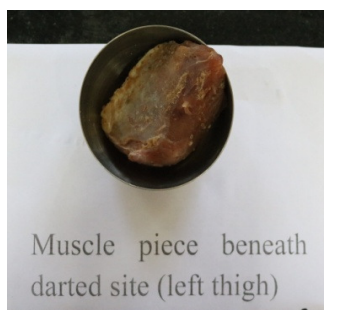

Figure 14. Darted site muscle piece

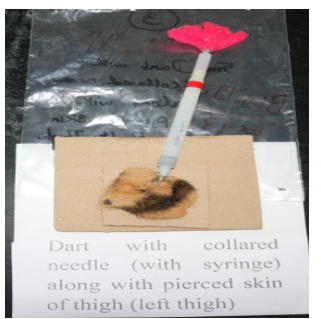

Figure 15. Skin Piece

Gas chromatography mass spectrometry method

GC-MS analysis of extracts from biological and non biological samples was performed on Agilent 7890B GC equipped with Leco Pegasus HT high throughput TOF MS. Column: Restek RTX-5 Capillary, 10 M, 0.18 mm ID.

Oven temperature program: Initial temperature $70{ }^{\circ} \mathrm{C}$, hold for $1 \mathrm{~min}$, then increased $15^{\circ} \mathrm{C} / \mathrm{min}$ to $280{ }^{\circ} \mathrm{C}$, hold for $5 \mathrm{~min}$.

$\begin{array}{ll}\text { Run time } & : 20 \mathrm{~min} . \\ \text { Injector temperature } & : 260{ }^{\circ} \mathrm{C} \\ \text { Transfer line temperature } & : 260{ }^{\circ} \mathrm{C} \\ \text { Detector } & : \text { Mass Detector } \\ \text { Mass range } & : 45-500 \mathrm{amu} \\ \text { Carrier gas } & : \text { Helium } \\ \text { Flow rate } & : 1.5 \mathrm{~mL} / \mathrm{min} . \\ \text { Injection mode } & : \text { Split Ratio }: 50\end{array}$

\section{Results and Discussion}

In this case, biological and non biological samples were analyzed by thin layer chromatography. Dragendorff's spray reagent showed positive response for dart site skin piece, dart site muscle piece and methanol extract of empty dart with needle which confirmed presence of ketamine and xylazine. While Viscera (Whole Stomach and Pieces of Kidneys, Lungs, Heart, Liver, Brain, Spleen), heart blood and thoracic blood samples do not show any response to TLC analysis. For confirmatory analysis, above solvent extract was purified by preparative TLC and extracted solvent was evaporated to dryness and reconstituted with methanol and passed through anhydrous sodium sulphate to remove inorganic phosphate and water content. The methanol extract were filtered with 0.22 micron syringe filter and injected for GC-MS. Dart site Skin piece (Figure 16(a), 16(b), 16(c)), dart site muscle piece (Figure 17(a), 17(b), 17(c)) and Methanol extract of empty Dart with needle (Figure 18(a), 18(b) \& 
18(C) showed the presence of ketamine and xylazine in GC-MS analysis. Gas chromatography mass spectrometry confirms presence of ketamine and xylazine in biological and non-biological exhibits like dart site skin piece, dart site muscle piece and methanol extract of empty dart with needle. While visceral tissue (Whole Stomach, Kidney, Lungs, Heart, Liver, Brain and Spleen), heart blood and thoracic blood samples do not reveal any peak of ketamine and xylazine in GC-MS chromatogram. As per the history of Tigress i.e. man eating Tigress, content in the stomach of Tigress also analysed for origin determination and it was found on human.

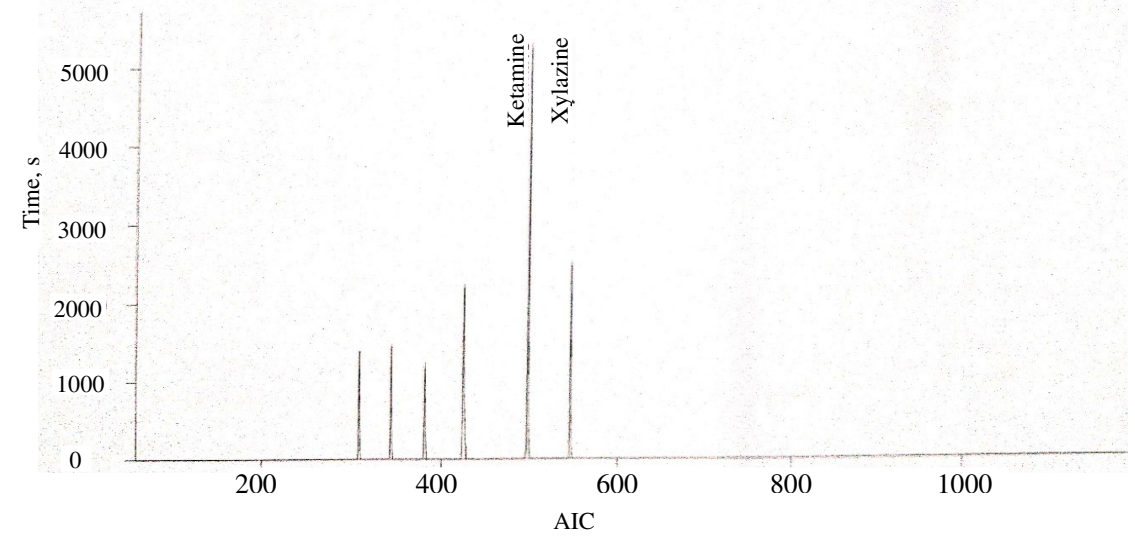

Figure 16(a). Gas chromatogram of skin piece

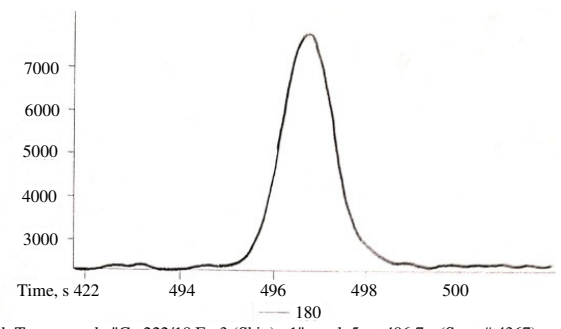

Peak True- sample "Cn 222/18 Ex 3 (Skin) : : 1", pẹak 5, at 496.7 s (Spec \# 4367)
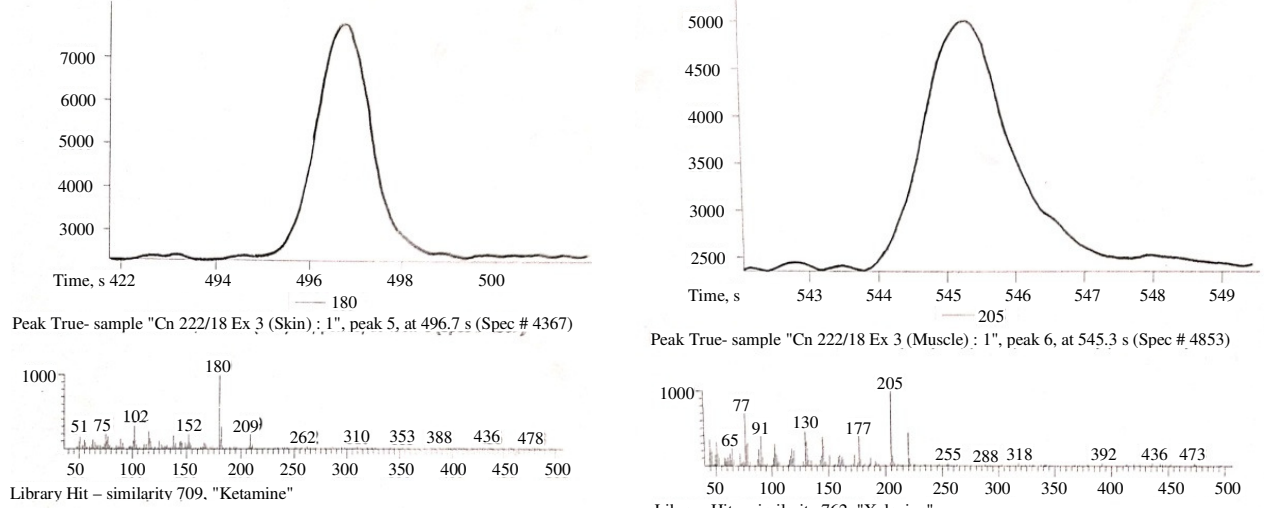

Peak True- sample "Cn 222/18 Ex 3 (Muscle) : 1", peak 6, at $545.3 \mathrm{~s}$ (Spec \# 4853)
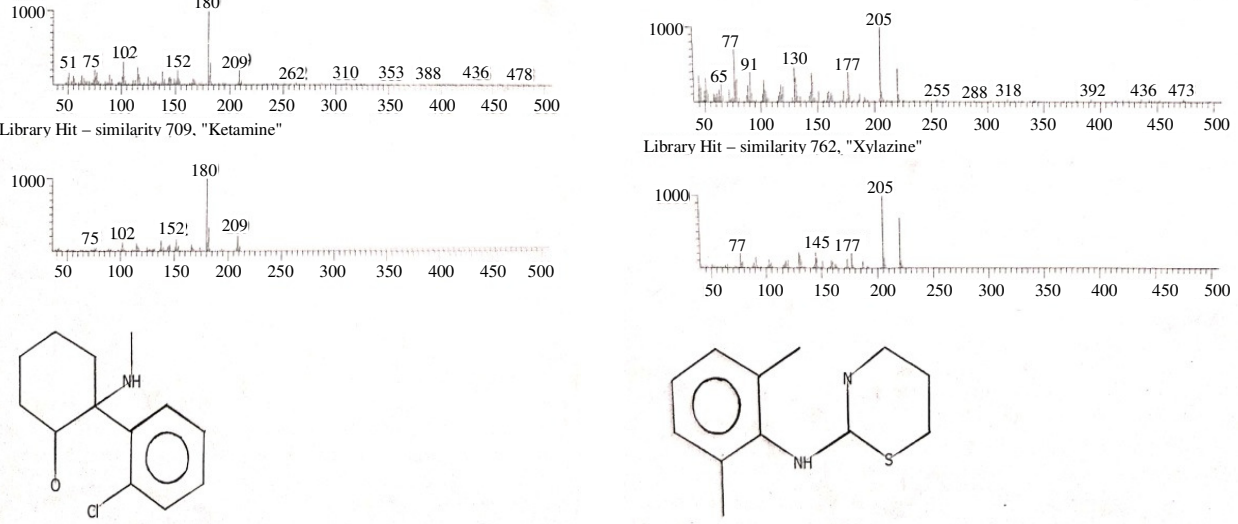

Figure 16(b). Mass spectrum of ketamine detected in skin piece

Figure 16@. Mass spectrum of xylazine detected in skin piece 


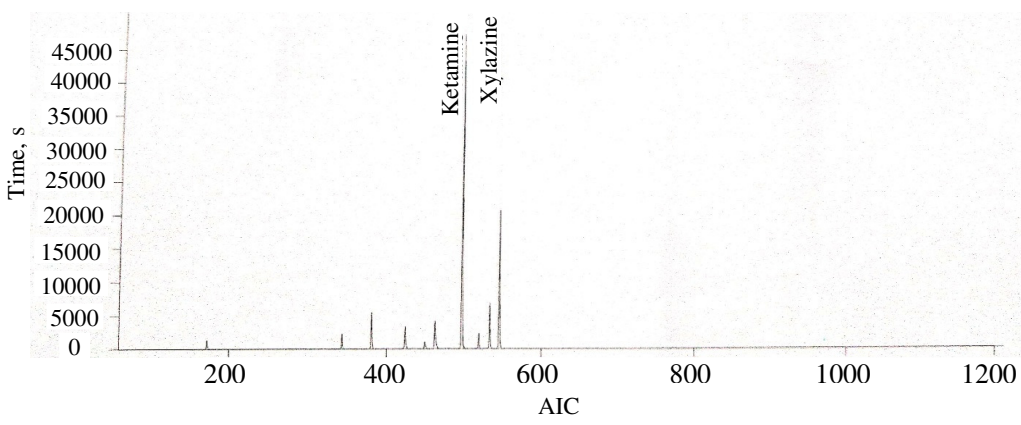

Figure 17(a). Gas chromatogram of muscle piece

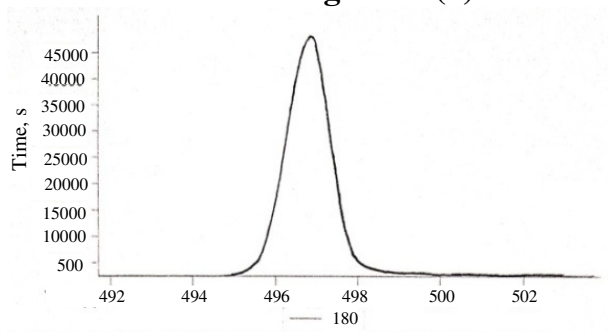

Peak true- sample "Cn 222/18 Ex 4 (Muscle) : 1", peak 8, at $496.8 \mathrm{~s}$ (Spec \# 4368)
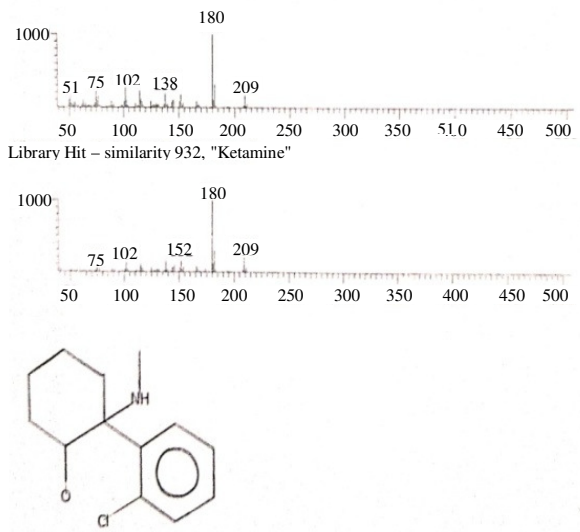

Figure 17(b). Mass spectrum of ketamine detected in muscle piece

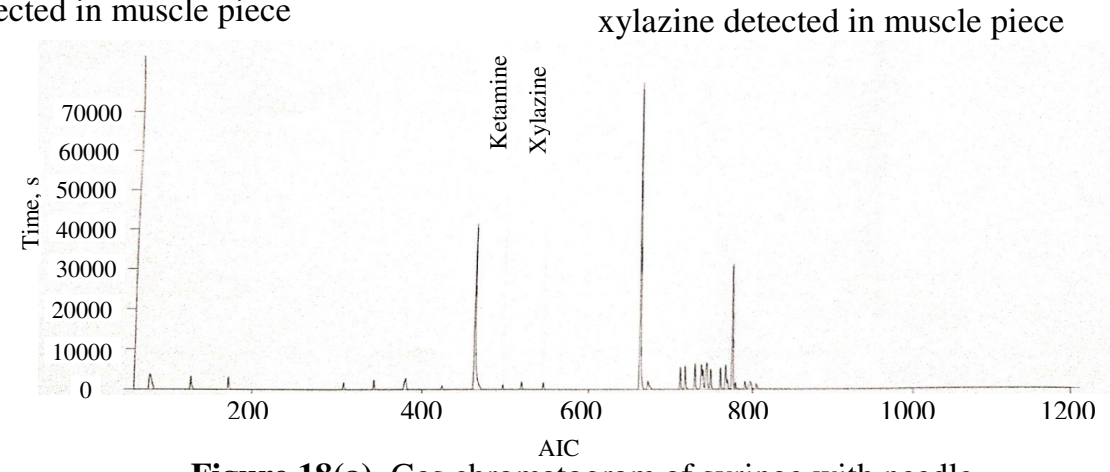

Figure 18(a). Gas chromatogram of syringe with needle

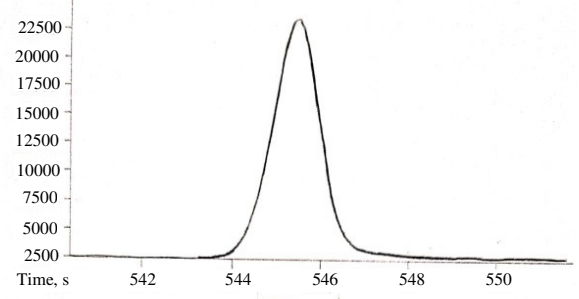

Peak True- sample "Cn 222/18 Ex 4 (Muscle) : 1", peak 11, at 545.5 s (Spec \# 4855)
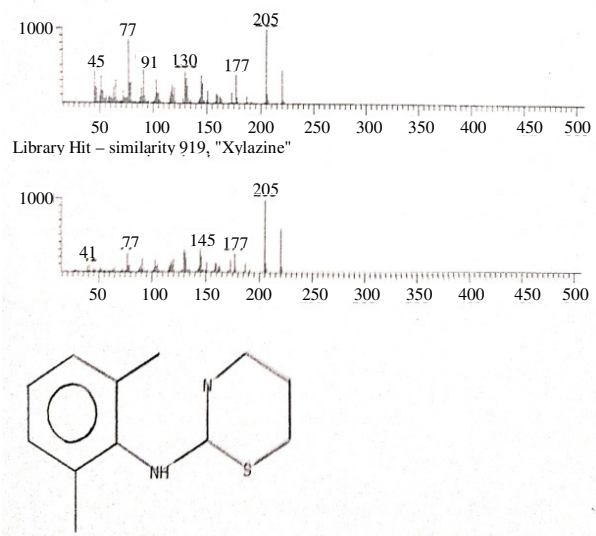

Figure 17(c). Mass spectrum of xylazine detected in muscle piece 


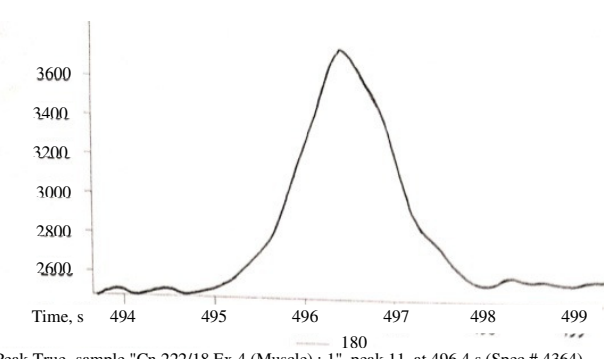

Peak True- sample "Cn 222/18 Ex 4 (Muscle) : 1", peak 11, at $496.4 \mathrm{~s}$ (Spec \# 4364)

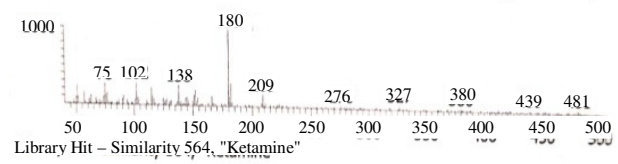

Peak True- sample "Cn 222/18 Ex 3 (Muscle) : 1", peak 13, at $545 \mathrm{~s} \mathrm{(Spec} \mathrm{\#} \mathrm{4850)}$
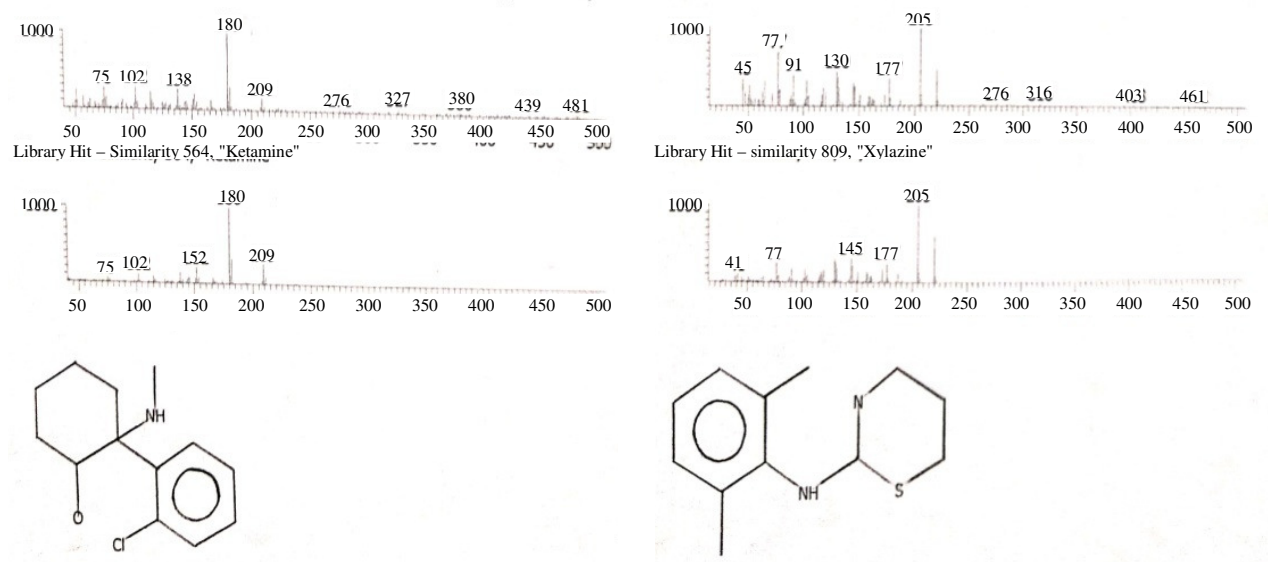

Figure 18(b). Mass spectrum of ketamine detected in syringe

Figure 18I. Mass spectrum of xylazine detected in syringe

\section{Conclusion}

In this paper, a simple, rapid, sensitive and reproducible method is used for the simultaneous determination of ketamine and xylazine from viscera, skin and muscle with single step liquid-liquid extraction procedure. The accurate identification was done by gas chromatography-mass spectrometry (GC-MS) techniques for the both anesthetic drugs, i.e. ketamine and xylazine in the above biological and non biological samples. Thus present study provides useful practical method for detection of two types of anesthetic drugs in both biological and non biological samples received in forensic science laboratory, which can be used as protocol for detection of ketamine and xylazine anesthetic drugs in medicolegal cases in near future.

\section{Acknowledgements}

The Authors wish to thank Dr. K. V. Kulkarni, Director, Directorate of Forensic Science Laboratories, State of Maharashtra, Mumbai, India, for encouraging and supporting us.

\section{References}

1. Reves J G, Glass P S, Lubarsky D A, McEvoy M D and Ruiz R M, Intravenous anaesthetics. In: Miller RD, Editor. Miller's Anaesthesia. $7^{\text {th }}$ Ed., USA: Churchill Livingstone; 2010. Pp. 719-771.

2. Muir W W, Skarda R T and Milne D W, Am J Vet Res., 1977, 38(2), 195-201.

3. Haskins S C, Farver T B and Patz J D, Am J Vet Res., 1985, 46, 1855-1860. 
4. White P F and Elig M R, Intravenous anaesthetics. In: Barash PG, Editor, Clinical Anaesthesia. $6^{\text {th }}$ Ed., China: Lippincott Williams and Wilkins; 2013, 478-500.

5. Kollias-Baker C A, Court M H and Williams L L, J Vet Pharmacol Ther., 1993, 16(3), 350-358; DOI:10.1111/j.1365-2885.1993.tb00182.x

6. Cuvelliez S, Rosseel G, Blais D, Salmon Y, Troney E and Lariviere N, Can Vet J., 1995, 36(10), 613-618.

7. Richard Sams and Pat Pizzo, J Analytical Toxicol., 1987, 11(2), 58-62; DOI:10.1093/jat/11.2.58 